\title{
Nasopharyngeal carriage rate of Streptococcus pneumoniae in Ugandan children with sickle cell disease
}

\author{
David P Kateete ${ }^{\dagger}$, Henry Kajumbula, Deogratias H Kaddu-Mulindwa and Augustine K Ssevviri ${ }^{* \dagger}$
}

\begin{abstract}
Background: Nasopharyngeal carriage of Streptococcus pneumoniae is a determinant for invasive pneumococcal disease, which often complicates homozygous sickle cell disease. Here, we determined the nasopharyngeal carriage rate of S. pneumoniae in Ugandan children with homozygous sickle cell disease, who attended the outpatient Sickle Cell Clinic at Mulago National Referral hospital in Kampala, Uganda.

Results: S. pneumoniae occurred in 27 of the 81 children with homozygous sickle cell disease (giving a carriage rate of $33 \%, 27 / 81)$. Twenty three children were previously hospitalized of whom S. pneumoniae occurred in only two $(9 \%, 2 / 23)$, while among the 58 who were not previously hospitalized it occurred in $25\left(43 \%, 25 / 58, \chi^{2}=8.8, p\right.$ $=0.003)$, meaning there is an association between high carriage rate and no hospitalization. Two children previously immunized with the pneumococcal conjugate vaccine did not carry the organism. Prior antimicrobial usage was reported in 53 children $(65 \%, 53 / 81)$. There was high resistance of pneumococci to penicillin $(100 \%, 27 /$ 27) and trimethoprime-sulfamethoxazole $(97 \%, 26 / 27)$, but low resistance to other antimicrobials. Of the 70 children without sickle cell disease, S. pneumoniae occurred in $38(54 \%, 38 / 70)$ of whom 43 were males and 27 females (53\% males, 23/43, and 56\% females, 15/27).

Conclusion: Nasopharyngeal carriage of penicillin resistant pneumococci in Ugandan children with homozygous sickle cell disease is high. While nasopharyngeal carriage of S. pneumoniae is a determinant for invasive pneumococcal disease, pneumococcal bacteremia is reportedly low in Ugandan children with sickle cell disease. Studies on the contribution of high carriage rates to invasive pneumococcal disease in these children will be helpful. This is the first report on pneumococcal carriage rate in Ugandan children with sickle cell disease.
\end{abstract}

\section{Background}

Sickle cell anemia, also known as homozygous sickle cell disease (genotype $\beta^{s} \beta^{s}[1]$ ) is prevalent in Uganda [2]. Invasive pneumococcal disease is one of the leading complications of homozygous sickle cell disease (HbSS) [3]. Patients with HbSS are more prone to pneumococcal meningitis $[4,5]$ and to pneumococcal septicemia $[6,7]$. Globally, the incidence of invasive pneumococcal disease in children with HbSS is 30- to 600-fold higher than in individuals of comparable age and race without HbSS; pneumococcal septicemia and meningitis are

\footnotetext{
* Correspondence: kaddu@chs.mak.ac.ug

+ Contributed equally

Department of Medical Microbiology, School of Biomedical Sciences,

Makerere University College of Health Sciences, Box 7072 Kampala, Uganda
}

important causes of death in HbSS patients, with case/ fatality rates of 15 to $35 \%$ [4,8-11].

There are varying reports of invasive pneumococcal disease in sub-Saharan African children with HbSS; in the Democratic Republic of Congo, S. pneumoniae was the most frequent isolate from HbSS patients with bacteremia $[2,12]$, and the organism was recovered from blood cultures of all the eight HbSS-patients with pneumonia in Northern Nigeria [13]. However, three other Nigerian studies [14-16] reported low prevalence of pneumococcal bacteremia in patients with HbSS. Further, S. pneumoniae bacteremia is reportedly very low in Ugandan children with HbSS [17].

Nasopharyngeal carriage of S. pneumoniae is the determinant for invasive pneumococcal disease particularly in industrialized settings $[18,19]$; therefore,
C Biomed Central 
investigation of pneumococcal colonization is important particularly in high risk groups such as HbSS patients. While pneumococcal bacteremia in Ugandan children with HbSS is low [17], pneumococcal carriage rates in these children have not been determined, yet carriage rates for healthy children are available (62\% prevalence [20]). Here we aimed to determine the nasopharyngeal carriage rate of $S$. pneumoniae in Ugandan children with HbSS attending the Sickle Cell Clinic at Mulago National Referral Hospital in Kampala, Uganda.

\section{Methods}

\section{Patient description and sampling}

This study took place over a 6 month period from December 2001 to May 2002. Eighty one children (51 males and 30 females, aged 8 months to 6 years, ascertained from patient records) with severe HbSS, attending the Sickle Cell Clinic at Mulago hospital in Kampala, Uganda, were recruited. Of these, 23 were previously admitted for treatment of low haemoglobin levels. All the children frequently visited the sickle cell clinic, which provides care to children confirmed with sickle cell anemia in Uganda (see references [2] and [17]). The youngest child was 8 months while the oldest was 6 years; the median age was 2.8 years. All the children had symptoms of severe HbSS disease based on clinical reports and symptoms. Records indicated that the children were on programmed routine visits to the clinic, although some reported whenever complications developed. The diagnosis of $\mathrm{HbSS}$ was based on an $\mathrm{FSA}_{2}$ pattern upon haemoglobin electrophoresis and characteristic haematology; haemoglobin electrophoresis testing was performed earlier on samples from these children and detected homozygous sickle cell disease (HbSS).

Parents or guardians signed an informed consent form and were interviewed on antimicrobial usage during the preceding one month and on the history of pneumococcal immunization (to determine their effects on recovery of pneumococci). The data on antimicrobial usage was verified by cross-checking with the information on prescription forms presented by the attendants. Nasopharyngeal specimens (one sample per child) were obtained by a paediatrician on duty using pre-packed sterile disposable calcium alginate fiber tipped-aluminum applicator swab. Children above 6 years were excluded (because they are less colonized by pneumococci [21]), as well as those who presented with severe ailments particularly pneumonia, and those who lacked consent from parents/guardians. Seventy children (2-6 years) with no history of HbSS from an outpatient ward were also sampled (controls) to compare the pneumococcal carriage rates. Symptoms of HbSS were missing in control subjects and they were considered not to have HbSS; however, they presented with fever and diarrhea, for which they sought care. For most children in Uganda, HbSS symptoms usually manifest within 6 months to 1 year after birth (unpublished observations); hence we excluded children less than 1 year among controls to minimize including those with HbSS disease.

\section{Culture and identification of S. Pneumoniae}

Nasopharyngeal specimens were immediately transported in Stuart's transport medium to the laboratory and cultured according to standard microbiological procedures. Briefly, the specimens were inoculated onto $5 \%$ rabbit blood agar plates and incubated for $24-48 \mathrm{~h}$ at $35-37^{\circ} \mathrm{C}$ under $5 \% \mathrm{CO}_{2}$. S. pneumoniae was identified based on colony morphology, $\alpha$-hemolysis and Gram staining and confirmed based on optochin sensitivity and bile solubility. Antimicrobial susceptibility was performed with bacterial suspensions of turbidity equivalent to McFarland 0.5 with the following disks (Oxoid, UK): oxacillin, $1 \mu \mathrm{g}$; erythromycin, $25 \mu \mathrm{g}$; ceftriaxone, $30 \mu \mathrm{g}$; chloramphenicol, $30 \mu \mathrm{g}$; trimethoprime-sulfamethoxazole, 23-75 $\mu \mathrm{g}$; rifampicin, $5 \mu \mathrm{g}$; and perfloxacin, $17 \mu \mathrm{g}$. Interpretation for sensitivity, intermediate or resistance was based on guidelines from the Clinical and Laboratory Standards Institute (CLSI). Controls included Staphylococcus aureus ATCC 25923 and Escherichia coli ATCC 29522.

Ethical approval was obtained from the Mulago Hospital Research and Ethics Committee, and the Faculty of Medicine Research and Ethics Review Board.

\section{Results and discussion}

S. pneumoniae occurred in 27 of the 81 children with HbSS (giving a nasopharyngeal carriage rate of 33\%, 27/ 81). Thus, in the current study a much higher S. pneumoniae carriage rate was found than in a previous report from the USA in which prevalence was reported to be $13 \%$ [3]. However, for healthy Ugandan children without HbSS, Joloba et al, found a significantly higher nasopharyngeal carriage rate (62\%) [20]. Of the 23 previously hospitalized children, pneumococci occurred in two $(2 / 23$, 9\%). Fifty eight children had not been hospitalized before, of whom pneumococci occurred in 25 , meaning there is an association between high carriage rate and no hospitalization $(25 / 58,43 \%, \chi 2=8.8, p=$ $0.003)$. There was no major difference in carriage rates between males and females (i.e., 35\%, 18/33 males vs. $30 \%, 9 / 23$ females). Of the 70 children without $\mathrm{HbSS}$, pneumococci occurred in $38(54 \%, 38 / 70)$ of whom 23 were males $(23 / 38,61 \%)$ and 15 females $(15 / 38,39 \%)$. Two children with HbSS had been immunized with a conjugate pneumococcal vaccine and did not carry the organism; pneumococcal immunization was not reported among children without HbSS. Fifty three children with HbSS reported antimicrobial usage (53/81, $65 \%$, Table 1) while it was reported by 43 children 
Table 1 Antimicrobial usage in Ugandan children with HbSS

\begin{tabular}{lllllllllll}
\hline Antimicrobial & & None & SXT & Pen & Amo/Clox & Aug & Amo/SXT & Amp & Chl & Cep \\
\hline S. pneumoniae carriers & $\mathbf{2 7}$ & 9 & 7 & $\mathbf{5}$ & 1 & 1 & 2 & 1 & 1 & - \\
\hline Non carriers & $\mathbf{5 4}$ & 19 & 12 & $\mathbf{4}$ & 4 & 3 & 4 & 5 & 2 & 1 \\
\hline TOTAL & $\mathbf{8 1}$ & 28 & 19 & $\mathbf{9}$ & 5 & 4 & 6 & 6 & 3 \\
\hline
\end{tabular}

SXT, trimethoprime-sulfamethoxazole; Pen, penicillin; Amo, amoxicillin; Clox, cloxacillin; Aug, Augmentin; Amo, amoxicillin; Amp, ampicillin; Chl, chloramphenicol; Cep, cephalexin; -, Not detected

without HbSS (43/70, 61\%). Antimicrobials commonly used included penicillins, sulphomexazole-trimethoprim, chloramphenicol and cephalexin (Table 1).

All isolates from children with $\mathrm{HbSS}$ were resistant to penicillin $(27 / 27,100 \%)$ while those from children without $\mathrm{HbSS}$ were intermediate $(38 / 38,100 \%)$. Resistance to sulphomexazole-trimethoprim was also high for both categories. However, the isolates from both groups were sensitive to the other commonly used antimicrobials (Table 2). These findings are similar to those of Joloba et al, who found high rates of penicillin and sulphomexazole-trimethoprim resistant S. pneumoniae [20]. However in this study, the isolates from children with HbSS were fully resistant to penicillin while those in the previous study were intermediate. The lower carriage rate and increased antimicrobial resistance to penicillin in the current study may be attributed to the common usage of penicillin in children with HbSS [20]. Nevertheless, there is no report on penicillin prophylaxis among sickle cell children in Uganda but the drug is widely prescribed [2] and can be purchased over the counter without prescription. Further, while penicillin prophylaxis in Uganda is recommended for children with $\mathrm{HbSS}$, it is not followed in principle since the drug is not free and some parents/guardians cannot afford it. Usually parents with the means to do so can easily obtain the drug over the counter. However, when the children are unwell the drug will almost certainly be taken, meaning that use of penicillin in this population is generally symptomatic rather than prophylactic. High carriage rates of antimicrobial resistant strains were also found in Zambia (Pneumococcus was reported in 71.9\% of the children [22]); however, $12.7 \%$ of the strains were resistant to penicillin [22]. The reason for the difference in resistance rates between Uganda and Zambia is likely due to law enforcement practices on antimicrobial usage.

Antimicrobial usage during the previous month did not significantly affect nasopharyngeal carriage rates $(p$ $=0.93$ ). However in previous studies, prior antimicrobial usage reduced the nasopharyngeal carriage of $S$. pneumoniae [23]. Of the $27 \mathrm{HbSS}$ children from whom $S$. pneumoniae was recovered, nine had not used antimicrobials; seven had used sulphomexazole-trimethoprim; five penicillin; one amoxicillin-cloxacillin; one Augmentin; two amoxicillin + sulphomexazole-trimethoprim; one ampicillin; one chloramphenicol and none used cephalexin. Of the $54 \mathrm{HbSS}$ children from whom $S$. pneumoniae was not recovered, 19 had not used antimicrobials; 12 had used sulphomexazole-trimethoprim; three penicillin; four amoxicillin-cloxacillin; three Augmentin; four amoxicillin + sulphomexazole-trimethoprim; five ampicillin; two chloramphenicol and one cephalexin. Of the 70 children without HbSS, 27 had not used any antimicrobial; 27 had taken sulphomexazole-trimethoprim; 12 penicillin; three chloramphenicol; and one amoxicillin + sulphomexazole-trimethoprim.

Despite the high nasopharyngeal carriage (which is a determinant for invasive pneumococci [18]), there is a puzzling discrepancy of high carriage rates with low rates of invasive pneumococcal disease in sub-Saharan Africa (see references [1,17]). Kizito et al [17] reported a significantly low rate of pneumococcal bacteremia in Ugandan children with sickle cell disease $(6 \%, 3 / 47)$

Table 2 Antimicrobial susceptibility patterns of pneumococci from Ugandan children with HbSS

\begin{tabular}{|c|c|c|c|c|c|c|}
\hline & HbSS & & & No HbSS & & \\
\hline Antimicrobial & Susceptible (\%) & Intermediate (\%) & Resistant (\%) & Susceptible (\%) & Intermediate (\%) & Resistant (\%) \\
\hline Penicillin & - & - & $27(100)$ & - & $38(100)$ & - \\
\hline SXT & - & $1(3)$ & $26(97)$ & - & $5(7)$ & $18(26)$ \\
\hline Chloramphenicol & $26(97)$ & - & $1(3)$ & $16(23)$ & $2(3)$ & $5(7)$ \\
\hline Erythromycin & $26(97)$ & - & $1(3)$ & $19(27)$ & $2(3)$ & $2(3)$ \\
\hline Rifampin & $27(100)$ & - & - & $23(33)$ & - & - \\
\hline Cefriaxone & $27(100)$ & - & - & $23(33)$ & - & - \\
\hline Perfloxacin & $17(100)$ & - & - & $23(33)$ & - & - \\
\hline
\end{tabular}

-, Not detected 
[17], and other studies have indicated low pneumococcal bacteremia in Nigerian children [1,14-16]. These could be a consequence of uncontrolled antimicrobial usage particularly in the urban populations in those countries. However, the high rates of pneumococcal bacteremia in children with/without sickle cell disease in neighboring Kenya [6], the Gambia [24], Ghana [25], and Mozambique [26] cast doubt on previous reports with low rates of invasive pneumococcal disease. Since laboratory facilities in sub-Saharan Africa are generally not well established [6,27], surveillance can be challenging particularly for fastidious organisms such as the pneumococcus. Moreover, certain invasive pneumococcal serotypes are difficult to detect in the nasopharynx. Further, since the largest population based retrospective study of bacteremia in Kenyan children with HbSS revealed high incidence of invasive pneumococci [6], contrary to current reports $[1,17]$, invasive pneumococcal disease may not be uncommon in sub-Saharan African children with HbSS.

One major limitation in this study was failure to determine the prevailing serotypes among HbSS patients, which we presume would most likely be similar to those described by Joloba et al (i.e., serogroups 6, 9, 14, 19, and 23) [20]. Further, due to limited resources, we were unable to extend the study beyond 6 months, and we did not confirm control subjects for the absence of HbSS disease but relied on absence of HbSS symptoms. This being the first report of nasopharyngeal carriage rate of pneumococci from Ugandan children with sickle cell disease, we hope that future studies will put these in consideration.

\section{Conclusions}

A high carriage rate of penicillin resistant S. pneumoniae has been found in Ugandan children with HbSS. This rate is similar to or higher than those in settings where nasopharyngeal carriage is the determinant for invasive pneumococcal disease in HbSS patients [3]. A puzzling finding in previous studies is the low level of pneumococcal bacteremia in Ugandan children with HbSS [17]. Accordingly, the usefulness of pneumococcal prophylaxis in Ugandan children with HbSS has been debated [17]. Since pneumococci are leading causes of childhood and adult bacteremia/mortality in sub-Saharan Africa [26,28-30], further studies are necessary to resolve the discrepancy between high nasopharyngeal carriage rates of pneumococci and invasiveness.

\section{Abbreviations}

$\beta^{s} \beta^{5}$ : Genotype for homozygous sickle cell disease encoding haemoglobin $S$ (Hbs an abnormal version of beta-globin); HbSS: Homozygous sickle cell disease; MakCHS: Makerere University College of Health Sciences.

\section{Acknowledgements}

We are indebted to Prof. C. Ndugwa, head of the sickle cell clinic, Department of Paediatrics, Makerere University College of Health Sciences, the children who participated, and Mulago hospital administration for permission to conduct this study. Gratitude to the Dep't of Medical Microbiology (MakCHS) for the invaluable support.

\section{Authors' contributions}

AKS conceived, planned and conducted the study; DPK and AKS wrote the manuscript; HK and DHK supervised the study and helped with data analysis. All authors read and approved the final version of the manuscript.

\section{Competing interests}

The authors declare that they have no competing interests.

Received: 6 October 2011 Accepted: 13 January 2012

Published: 13 January 2012

\section{References}

1. Battersby AJ, Knox-Macaulay HH, Carrol ED: Susceptibility to invasive bacterial infections in children with sickle cell disease. Pediatr Blood Cancer 2010, 55(3):401-406.

2. Serjeant GR, Ndugwa CM: Sickle cell disease in Uganda: a time for action. East Afr Med J 2003, 80(7):384-387.

3. Daw NC, Wilimas JA, Wang WC, Presbury GJ, Joyner RE, Harris SC, Davis Y, Chen G, Chesney PJ: Nasopharyngeal carriage of penicillin-resistant Streptococcus pneumoniae in children with sickle cell disease. Pediatrics 1997, 99(4):E7.

4. Barrett-Connor E: Bacterial infection and sickle cell anemia. An analysis of 250 infections in 166 patients and a review of the literature. Medicine (Baltimore) 1971, 50(2):97-112.

5. Robinson MG, Watson RJ: Pneumococcal meningitis in sickle-cell anemia. N Engl J Med 1966, 274(18):1006-1008.

6. Williams TN, Uyoga S, Macharia A, Ndila C, McAuley CF, Opi DH, Mwarumba S, Makani J, Komba A, Ndiritu MN, et al: Bacteraemia in Kenyan children with sickle-cell anaemia: a retrospective cohort and casecontrol study. Lancet 2009, 374(9698):1364-1370.

7. Lobel JS, Bove KE: Clinicopathologic characteristics of septicemia in sickle cell disease. Am J Dis Child 1982, 136(6):543-547.

8. Halasa NB, Shankar SM, Talbot TR, Arbogast PG, Mitchel EF, Wang WC, Schaffner W, Craig AS, Griffin MR: Incidence of Invasive Pneumococcal Disease among Individuals with Sickle Cell Disease before and after the Introduction of the Pneumococcal Conjugate Vaccine. Clin Infect Dis 2007, 44(11):1428-1433.

9. Hord J, Byrd R, Stowe L, Windsor B, Smith-Whitley K: Streptococcus pneumoniae sepsis and meningitis during the penicillin prophylaxis era in children with sickle cell disease. J Pediatr Hematol Oncol 2002, 24(6):470-472.

10. Leikin SL, Gallagher D, Kinney TR, Sloane D, Klug P, Rida W: Mortality in children and adolescents with sickle cell disease Cooperative Study of Sickle Cell Disease. Pediatrics 1989, 84(3):500-508.

11. Wong W-Y, Overturf GD, Powars DR: Infection Caused by Streptococcus pneumoniae in children with sickle cell disease: Epidemiology, Immunologic Mechanisms, Prophylaxis, and Vaccination. Clin Infect Dis 1992, 14(5):1124-1136.

12. Eeckels R, Gatti F, Renoirte AM: Abnormal distribution of haemoglobin genotypes in Negro children with severe bacterial infections. Nature 1967, 216(5113):382.

13. Falade AG, Lagunju IA, Bakare RA, Odekanmi AA, Adegbola RA: Invasive pneumococcal disease in children aged $<5$ Years Admitted to 3 urban hospitals in Ibadan, Nigeria. Clin Infect Dis 2009, 48:S190-S196.

14. Akuse RM: Variation in the pattern of bacterial infection in patients with sickle cell disease requiring admission. J Trop Pediatr 1996, 42(6):318-323.

15. Okuonghae HO, Nwankwo MU, Offor EC: Pattern of bacteraemia in febrile children with sickle cell anaemia. Ann Trop Paediatr 1993, 13(1):55-64.

16. Akinyanju O, Johnson AO: Acute illness in Nigerian children with sickle cell anaemia. Ann Trop Paediatr 1987, 7(3):181-186.

17. Kizito ME, Mworozi E, Ndugwa C, Serjeant GR: Bacteraemia in homozygous sickle cell disease in Africa: is pneumococcal prophylaxis justified? Arch Dis Child 2007, 92(1):21-23. 
18. Bogaert D, De Groot R, Hermans PW: Streptococcus pneumoniae colonisation: the key to pneumococcal disease. Lancet Infect Dis 2004, 4(3):144-154.

19. Chesney PJ: The escalating problem of antimicrobial resistance in Streptococcus pneumoniae. Am J Dis Child 1992, 146(8):912-916.

20. Joloba ML, Bajaksouzian S, Palavecino E, Whalen C, Jacobs MR: High prevalence of carriage of antibiotic-resistant Streptococcus pneumoniae in children in Kampala Uganda. Int J Antimicrob Agents 2001, 17(5):395-400.

21. O'Brien KL, Wolfson LJ, Watt JP, Henkle E, Deloria-Knoll M, McCall N, Lee E, Mulholland K, Levine OS, Cherian T: Burden of disease caused by Streptococcus pneumoniae in children younger than 5 years: global estimates. Lancet 2009, 374(9693):893-902.

22. Woolfson A, Huebner R, Wasas A, Chola S, Godfrey-Faussett P, Klugman K: Nasopharyngeal carriage of community-acquired, antibiotic-resistant Streptococcus pneumoniae in a Zambian paediatric population. Bull World Health Organ 1997, 75(5):453-462.

23. Schrag SJ, Beall B, Dowell SF: Limiting the spread of resistant pneumococci: biological and epidemiologic evidence for the effectiveness of alternative interventions. Clin Microbiol Rev 2000, 13(4):588-601.

24. Kwambana BA, Barer MR, Bottomley C, Adegbola RA, Antonio M: Early acquisition and high nasopharyngeal co-colonisation by Streptococcus pneumoniae and three respiratory pathogens amongst Gambian newborns and infants. BMC Infect Dis 2011, 11:175.

25. Donkor ES, Newman MJ, Oliver-Commey J, Bannerman E, Dayie NT, Badoe EV: Invasive disease and paediatric carriage of Streptococcus pneumoniae in Ghana. Scand J Infect Dis 2010, 42(4):254-259.

26. Sigauque B, Roca A, Mandomando I, Morais L, Quinto L, Sacarlal J, Macete E, Nhamposa T, Machevo S, Aide P, et al: Community-acquired bacteremia among children admitted to a rural hospital in Mozambique. Pediatr Infect Dis J 2009, 28(2):108-113.

27. Petti CA, Polage CR, Quinn TC, Ronald AR, Sande MA: Laboratory medicine in Africa: a barrier to effective health care. Clin Infect Dis 2006, 42(3):377-382.

28. Bachou H, Tylleskar T, Kaddu-Mulindwa DH, Tumwine JK: Bacteraemia among severely malnourished children infected and uninfected with the human immunodeficiency virus-1 in Kampala Uganda. BMC Infect Dis 2006, 6:160.

29. Obaro S, Lawson L, Essen U, Ibrahim K, Brooks K, Otuneye A, Shetima D, Ahmed P, Ajose T, Olugbile M, et al: Community acquired bacteremia in young children from central Nigeria-a pilot study. BMC Infect Dis 2011, 11:137.

30. Hill P, Onyeama C, Ikumapayi U, Secka O, Ameyaw S, Simmonds N, Donkor S, Howie S, Tapgun M, Corrah T, et al: Bacteraemia in patients admitted to an urban hospital in West Africa. BMC Infect Dis 2007, 7(1):2.

doi:10.1186/1756-0500-5-28

Cite this article as: Kateete et al:: Nasopharyngeal carriage rate of Streptococcus pneumoniae in Ugandan children with sickle cell disease. BMC Research Notes 2012 5:28.

\section{Submit your next manuscript to BioMed Central and take full advantage of:}

- Convenient online submission

- Thorough peer review

- No space constraints or color figure charges

- Immediate publication on acceptance

- Inclusion in PubMed, CAS, Scopus and Google Scholar

- Research which is freely available for redistribution

Submit your manuscript at www.biomedcentral.com/submit
Biomed Central 